\title{
The Transdisciplinary Engineering Index: Towards a Disciplinary Maturity Grid
}

\author{
Susan LATTANZIO ${ }^{\mathrm{a}, 1}$, Emily CAREY ${ }^{\mathrm{a}}$, Alex HULTIN ${ }^{\mathrm{a}}$, Reza IMANI ASRAI ${ }^{\mathrm{b}}$, Aydin \\ NASSEHI $^{\mathrm{b}}$, Glenn PARRY ${ }^{\mathrm{c}}$ and Linda NEWNES ${ }^{\mathrm{a}}$ \\ ${ }^{\text {a }}$ The University of Bath, Bath, UK \\ ${ }^{b}$ The University of Bristol, Bristol, UK \\ ${ }^{c}$ The University of Surrey, Surrey, UK
}

\begin{abstract}
The adoption of transdisciplinary capabilities within UK manufacturing could strengthen resilience in response to system disruptions. We propose a Disciplinary Maturity Grid (DMG) as a means through which industry can assess the disciplinarity of their engineering capability. The design of methods to assess maturity of disciplinary working is hindered by a lack of empirical evidence to support identification of the important dimensions. A workshop involving twelve academic experts was used to create a maturity grid. Workshop tasks focussed on defining the appropriate number of maturity levels, the dimensions of those levels, and the maturity assessment questions. The DMG contains five maturity levels and seven dimensions, providing a preliminary design from which to build in future studies.
\end{abstract}

Keywords. Transdisciplinary Engineering, Disciplinary Maturity Grid

\section{Introduction}

Manufacturing plays a significant role in the UK economy, contributing $£ 191$ billion of economic output (10\% of the UK total), and employing 2.7 million people ( $8 \%$ of jobs) [1]. UK government aims to ensure the resilience of the sector in the face of challenges including plateauing productivity levels and a widening trade deficit in manufactured goods, together with uncertainty around the UK leaving the European Union. In support of this aim in 2011 UK Research and Innovation (UKRI) initiated the Manufacturing the Future Challenge theme. Under this theme funding awards in excess of $£ 300$ million have been pledged to support research in three priority areas: drawing on opportunities from emerging research, promoting collaboration between academia and innovative manufacturing businesses, and fostering a research community with the appropriate skills and leadership in manufacturing research [2].

UKRI recognised the potential benefits from adoption of transdisciplinarity within manufacturing and in 2018, under the Manufacturing the Future Challenge, awarded $£ 1.8 \mathrm{~m}$ for research focussed on enabling transdisciplinary working within the sector [3]. Under the terms of the award the ultimate ambition is to design and validate a Transdisciplinary Engineering (TE) Index [4]. The Index will comprise of three elements: a means for industry to assess their current disciplinary state; a means for industry to assess the level of disciplinarity that is required; and tools to help them move

\footnotetext{
${ }^{1}$ Corresponding Author, Mail: s12091@bath.ac.uk.
} 
from one level to another. The focus of this paper is the first of these three elements - a means for industry to assess their current disciplinary state. This is approached through the creation of a Disciplinary Maturity Grid (Figure 1).

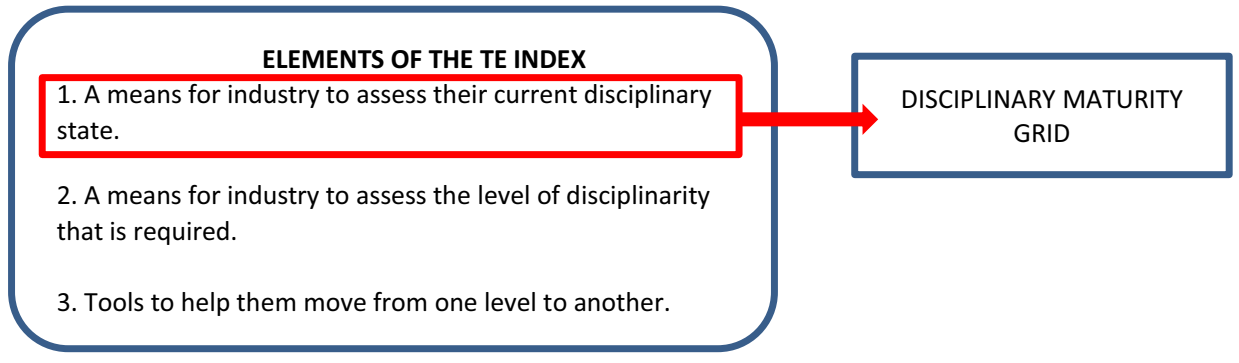

Figure 1. Mapping the elements of the TE Index to the Disciplinary Maturity Grid.

Within this paper we present the results of a workshop undertaken as a means to create a Disciplinary Maturity Grid (DMG). Specific design aspects include the number of maturity levels, the number and focus of the dimensions, definition of the maturity assessment questions. The paper is structured as follows: First the background literature is presented (Section 1). The methodology and processes followed within the workshop are described (Section 2). The DMG created within the workshop is presented (Section 3 ) and discussed in light of the literature (Section 4). Finally, conclusions are formulated, and future work identified (Section 5).

\section{Background}

Since its emergence in the 1970s, transdisciplinarity has been positioned as a level of working which exceeds interdisciplinarity [5]. Although there is no universally accepted definition, transdisciplinarity is often characterised as an approach which brings together academic and stakeholder perspectives and integrates physical and social sciences to understand the context in which a challenge exists [6-10].

Transdisciplinary approaches are considered to be particularly useful in dealing with complex challenges. In the 1990s, a growing concern for the environment, a challenge that requires many different disciplines to address, brought with it a requirement for new ways of working, and transdisciplinarity came to the fore [11, 12]. From this point forwards the number of published papers referencing the term are seen to accelerate [13]. Subsequently, new technologies and Industry 4.0 have led to increasingly complex engineering systems. This has resulted in interest in transdisciplinary working from the engineering academic and research funding communities [13]. There is also evidence that transdisciplinarity has been embraced by practitioners [14, 15]. However, how theory can be operationalised within industry setting requires research.

One of the challenges in operationalisation of transdisciplinarity is the lack of a universal definition [8, 16-18]. What is generally accepted is that there is a hierarchy of disciplinarities, which starts with a single discipline, progresses through multi- and interand ends with transdisciplinarity $[7,8]$. By aiming to understand at which disciplinary state(s) a company is currently capable of working, it is in fact creating a measure of disciplinary 'maturity'. Maturity is the capability to consistently achieve organisational 
objectives. To deliver on this, a company should be able to work appropriately at all levels of the hierarchy. This raises the question: What approaches have been used to assess maturity?

\subsection{Maturity Assessments}

Maturity assessments are extensively used within industry both as an informed approach for continual improvement and as a means for self or third party assessment [19]. As shown by the review conducted by Maier, Moultrie [20], assessments have an extremely broad focus and consider all manner of organisational aspects including, but not limited to, quality management, project management, capability, safety, research and development effectiveness, information security, innovation, and communication.

Although the term 'model' is often used as a catch-all, the literature identifies two distinct types of maturity assessments: Capability Maturity Models (CMM)-like models, and Maturity grids / Likert-like questionnaires [20,21]. CMM-like models identify 'best practice' in a specific process and measure against how many of these practices the organisation demonstrates. They often follow a formal format allowing them to be used in certification of performance [20,21]. In contrast maturity grids are simpler. Presented as a matrix they provide a text description for defined activities or dimensions at each maturity level. Likert-like questionnaires are similar to maturity grids but rather than provide descriptions at each level of maturity, assessments are based on performance against a statement of good practice. Unlike the CMM model, maturity grids do not usually aspire to provide certification and can be used as a stand-alone assessment or as part of a wider initiative [20,21].

In the context of a TE Index a grid is preferable to a CMM-like model for two main reasons. First, the CMM-like model is built on the belief that there is a best practice. When it comes to disciplinarity we assert that there is no best practice, rather different disciplinarities will be more or less appropriate depending on context. Second, a matrix is simpler and has a less prescriptive format than a CMM-like model. In this way it is more suitable for self-assessment and offers more flexibility for combining with the other elements required to form the Index. Having decided a grid is most suitable we ask, what are the main design elements of a grid?

\subsection{Design elements of a maturity grid}

Grids are presented as a matrix, each having a number of maturity levels, and a number of dimensions (the areas which are considered), with assessment questions to evaluate the maturity level of each dimension. Figure 2 presents an example maturity grid, the Energy Management Matrix, produced by the Carbon Trust. The figure is annotated to identify the three common grid elements: maturity levels, dimensions, and maturity assessment questions.

Figure 2 shows The Energy Management Matrix has five maturity levels and six dimensions. However, there is no set format and the number of levels and the dimensions included can vary [22]. A common criticisms of maturity grids is that they rarely describe how the grid was developed. The occasional papers where a method is provided demonstrate a mix of approaches which aim to bring together literature with expert opinion [22]. Maturity assessments have been criticised for a lack of rigour during their design. There have been some efforts in proposing maturity assessments design methodologies [19, 22-28]. Although with individual nuances, studies by Metler (2011) 
and García-Mireles, Moraga [29] have found the different methodologies contain common steps. Garcia-Mireles et al. define four steps: establish goals for maturity model development, design model architecture, set out capability levels and dimensions, and pilot testing. Metler identifies five steps: identify need or new opportunity; define scope; design model; evaluate design; and reflect evolution. Although similar, where the two studies differ is that Garcia-Mireles et al. found a lack of reference within the proposed methodologies to specific activities for maintenance.

\section{DIMENSIONS}

\begin{tabular}{|c|c|c|c|c|c|c|}
\hline & $\begin{array}{l}\text { Energy } \\
\text { Policy }\end{array}$ & Organising & Training & $\begin{array}{l}\text { Performance } \\
\text { Measurement }\end{array}$ & Communication & Investment \\
\hline 4 & $\begin{array}{lr}\text { Energy } & \text { Policy, } \\
\text { Action Plan and } \\
\text { regular reviews } \\
\text { have active } \\
\text { commitment of top } \\
\text { management }\end{array}$ & $\begin{array}{l}\text { Fully integrated into } \\
\text { senior management } \\
\text { structure with clear } \\
\text { accountability for } \\
\text { energy consumption }\end{array}$ & $\begin{array}{l}\text { Appropriate and } \\
\text { comprehensive staff } \\
\text { training tailored to } \\
\text { identified needs, with } \\
\text { evaluation. }\end{array}$ & $\begin{array}{l}\text { Comprehensive } \\
\text { performance } \\
\text { measurement against } \\
\text { targets within effective } \\
\text { management reporting. }\end{array}$ & $\begin{array}{l}\text { Extensive communication } \\
\text { of energy issues within } \\
\text { and outside of the } \\
\text { company. }\end{array}$ & \\
\hline 3 & $\begin{array}{l}\text { Formal policy but } \\
\text { no active } \\
\text { commitment from } \\
\text { top management }\end{array}$ & \begin{tabular}{lr}
\multicolumn{2}{c}{ Clear line management } \\
accountability & for \\
consumption & and \\
responsibility & for \\
improvement &
\end{tabular} & $\begin{array}{l}\text { Energy training } \\
\text { targeted at major users } \\
\text { following training } \\
\text { needs analysis }\end{array}$ & & & \\
\hline 2 & Un-adopted policy & $\begin{array}{l}\text { Some delegation } \\
\text { responsibility }\end{array}$ & & & $\begin{array}{l}\text { ganisational } \\
\text { memmunication } \\
\text { mechanisms to promote } \\
\text { energy efficiency }\end{array}$ & $\begin{array}{l}\text { Low or medium } \\
\text { cost measures } \\
\text { considered if short } \\
\text { payback period }\end{array}$ \\
\hline $\mathbf{0}$ & $\begin{array}{l}\text { No } \\
\text { polic }\end{array}$ & $\begin{array}{r}\text { of } \\
\text { for } \\
\text { energy }\end{array}$ & $\begin{array}{l}\text { No energy related staff } \\
\text { training provided }\end{array}$ & $\begin{array}{ll}\text { No measurement } & \text { of } \\
\text { energy costs } & \text { or } \\
\text { consumption } & \end{array}$ & $\begin{array}{l}\text { No communication or } \\
\text { promotion of energy } \\
\text { issues }\end{array}$ & $\begin{array}{l}\text { No investment in } \\
\text { providing energy } \\
\text { efficiency }\end{array}$ \\
\hline
\end{tabular}

Figure 2. Energy Management Matrix [30].

\section{Method}

The TREND Research Group seeks to create and validate a TE Index and use this as a means to enable transdisciplinarity within the manufacturing sector. The focus of this paper is the first element of the Index, the creation of a Disciplinary Maturity Grid through which industry can assess their current disciplinary state. The methodology through which the grid is created is now presented.

\subsection{Methodology}

TREND recognise the design of a maturity grid to be an iterative process in which a preliminary grid is created, evaluated and then evolved. As such, the five steps defined by Melter were selected as the approach to be followed in the design of the Disciplinary Maturity Grid (Figure 3).

Figure 3 details the design steps, showing the iterative nature of the development. In Step 1, identify need / new opportunity, was addressed within the funding request bid documentation, that identified a need within UK manufacture to develop TD capability. Step 2, define the scope (e.g. the focus and audience), was constrained by the terms of the funding award. Step 3, Design model, is undertaken by way of the workshop described in this paper. Evaluation of the design (Step 4), and reflect evolution (Step 5), will be undertaken as future work. 


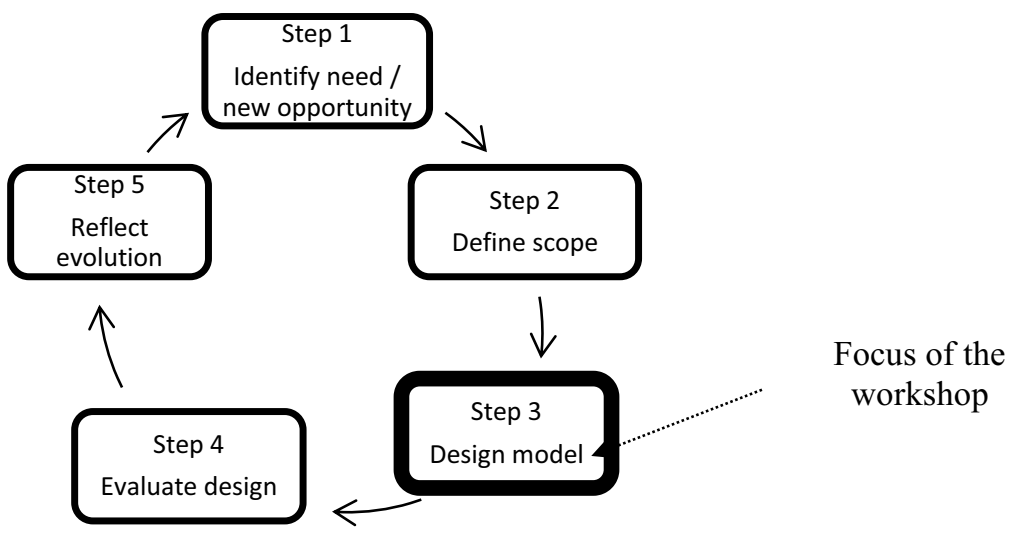

Figure 3. Disciplinary Maturity Grid Methodology.

Although Figure 3 presents the overall research methodology, it does not provide the detail of why a workshop approach was used, or how the workshop was organised. This detail follows.

\subsection{The Workshop}

Workshops are a widely used research approach that seeks to bring about an outcome, such as generating insights, or contributing to the design of a product, process, or innovation [31]. A common feature of workshops is the bringing together of a small number of people with experience in a certain domain [31]. The workshop participants here comprised of twelve members of the TREND research group, all experienced in transdisciplinary concepts and research. The choice to limit the workshop to only academic participants was based on the research of Carey [15] which highlights that TD has not widely penetrated industry. Table 1 provides details of the participants.

Table 1. Workshop participants.

\begin{tabular}{|l|c|c|c|}
\hline Position & University of Bath & University of Bristol & University of Surrey \\
\hline Academics & 3 & 3 & 1 \\
\hline Researchers & 3 & 1 & 0 \\
\hline PhD students & 1 & 0 & 0 \\
\hline
\end{tabular}

The desired outcome of the workshop was to create a Disciplinary Maturity Grid (DMG). Literature identifies that maturity grids have three common elements (maturity levels, dimensions, and maturity assessment questions). In designing the DMG, three design aspects were addressed: The number of maturity levels, the dimensions to be included, and how the maturity assessment questions would be defined. These aspects are now addressed in order.

\subsubsection{How many maturity levels should the grid have?}

Typically assessments are seen to have between three and six maturity levels [21], with the most common number being five [20]. With no literature to support the optimum 
number, a decision was made that the Disciplinary Maturity Grid would contain five maturity levels.

\subsubsection{What dimensions should be included?}

Although the number of maturity levels is generally consistent, the number and areas defined as the grid dimensions have a considerable range with examples found in the literature ranging from four to over one hundred [20]. If a maturity grid is being developed in an area which is mature, it is likely that there will be literature on the critical areas and in some cases existing models which can be built upon [23]. In an emerging domain, as is the case for transdisciplinarity within an engineering context, this body of evidence is not available

In designing the Disciplinary Maturity Grid ensuring that the relevant dimensions are included will be fundamental to its success. To uncover these dimensions a research experiment was undertaken. This experiment is presented in detail in the work of Hultin, et al. (2021), but in summary it involved an automated search of Scopus to identify all the papers with the term transdisciplinary or trans-disciplinary in the title, abstract or keywords. The abstracts were then analysed to extract any nouns directly following the term 'transdisciplinary' or 'trans-disciplinary'. The 100 most common terms, $(70.3 \%$ of term frequency), were subjected to a card sorting experiment whereby 20 TD subjectmatter experts individually sorted the terms into clusters comprising of similar terms. A categorical clustering algorithm was then used to identify the optimal grouping.

Within the workshop a Delphi like approach was used to name the clusters and these became the dimension names. The process used in naming the clusters follows:

- Workshop participants put into breakout rooms (3 groups x 4 people) and asked to discuss the clusters.

- Participants brought back to main room to discuss as a group.

- Participants put back into breakout rooms and asked to discuss again.

- Participants individually asked to come up with clusters names and enter them onto Padlet, (Microsoft collaboration tool).

- The workshop facilitator entered responses for each cluster (duplicates removed) into Mentimeter (a platform which enables live polls).

- Participants asked to vote for up to three names per cluster.

- Participants brought back to main room to discuss as a group.

- Top three names (or four in case of a tie in $3^{\text {rd }}$ place) with more than 2 votes, retained on Mentimeter.

- Second round of voting. Participants asked to vote (max. two names per cluster).

- Cluster name with the highest number of votes identified.

\subsubsection{How should the maturity assessment questions be defined?}

Research by de Bruin, Rosemann [23] identifies that when designing the maturity assessment questions, the literature provides a starting point. However, for richness the literature should be considered alongside other inputs. Figure 4 presents the inputs brought together in defining the maturity assessment questions. 


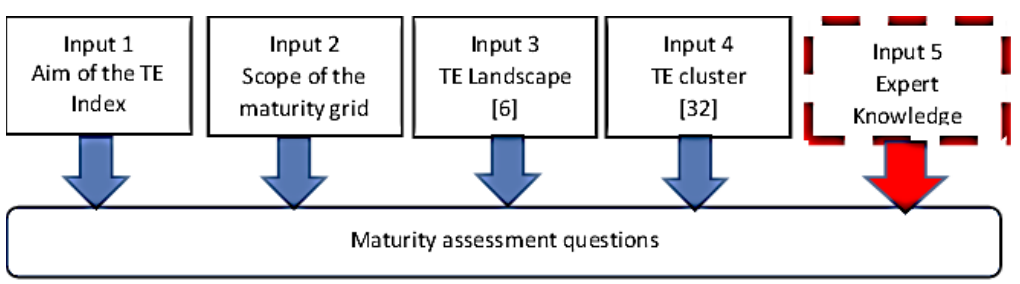

Figure 4. Inputs informing the maturity assessment questions.

Figure 4 shows the five inputs which inform the definitions of the maturity text descriptions. Aim and scope (Inputs $1 \& 2$ ) are defined and constrained by the terms of the funding award. The TE Landscape and TE clusters (Inputs 3 \& 4) bring the understanding gained through prior research studies. Finally, Input 5 recognises the contribution made by way of expert knowledge and expertise of the participants. The process for defining the maturity assessment questions follows:

- Activity introduced by independent workshop facilitator including presenting a worked example of assessment questions for one dimension.

- Participants put into breakout groups (3 groups x 4 people) and asked to discuss and critique the worked example.

- Participants brought back to the group to discuss.

- Participants put back into breakout groups. Each group asked to define assessment questions for one dimension.

- Participants brought back to the group to discuss.

- Participants put back into breakout groups. Each group asked to define assessment questions for a second dimension.

\section{The Disciplinary Maturity Grid}

The preliminary Disciplinary Maturity Grid created through the workshop is presented in Appendix 1.

\section{Discussion}

The aim of this research was to populate a first draft Disciplinary Maturity Grid this involved design decisions around the number of maturity levels, the dimensions, and how the assessment questions are defined.

The literature highlights that little attention is given to how the number of levels within a grid is decided. In the absence of a more rigorous approach it was agreed that the Disciplinary Maturity Grid would have five levels, thus reflecting what Maier, Moultrie [20] found to be the most common number. Despite making this design decision, for two of the dimension's maturity assessment questions, six levels were defined. This raises the question can the different levels for these dimensions be adequately encapsulated within five levels or are more levels necessary? Although, in each of the examples provided by Maier, et al. the number of dimensions was consistent across each of the dimensions, within a disciplinary maturity grid should/could the different dimensions have a different number of levels? 
Similar to the number of levels, within the literature there was little discussion of how the dimensions were selected. On the rare occasions where this was provided it was justified as being evidenced through the literature, or chosen based on the input of experts [22]. Within this work we used the literature and extracted the types of things which have been given the label of transdisciplinary. Although a rigorous approach to identify clusters of transdisciplinary 'things', do these translate to be the important dimensions?

Through a collaborative approach and utilising various input sources the participants were able to define the maturity assessment questions. However, during this process a specific question arose - should the assessment questions be phrased as objective or subjective measurements? Within the literature this question is given little consideration. Indeed, within the work of Mettler [32], which seeks to define the parameters which should be considered when designing a maturity assessment, although the question of "application of method" (i.e. whether the grid is completed as a self-assessment, with the assistance of a third party, or certified professionals), and the "respondents" (management, staff, business partners etc.) are both included, the specifics of whether the questions used in the assessment of maturity are objective or subjective is not.

\section{Conclusions and Future Work}

The aim of this work is to provide industry with a means through which to assess their current level of disciplinary working. Through the literature we identify that a hierarchy of disciplinarities exist and propose that in assessing disciplinarity it is in effect a measure of maturity. Using a workshop approach, we bring together understanding of the constraints, evidence from prior research studies, and expert knowledge to create a preliminary Disciplinary Maturity Gird. The grid comprises five maturity levels and seven dimensions (situation/stakeholders, perspective, knowledge, communication, the project, the approach, and activities).

The creation of a valid maturity grid is one element in the creation of TE Index and the operationalisation of transdisciplinary working with industry. However, it is recognised that the design of a maturity grid is an iterative process. This is especially true here where there is a lack of prior understanding of the dimensions which are fundamental to the success of transdisciplinary working. To this end future verification and validation studies will adopt a TD approach in which the perspectives of industry who will use the grid are captured and incorporated.

\section{Acknowledgements}

The work reported in this paper was undertaken as part of the Designing the Future: Resilient Trans-Disciplinary Design Engineers Project, at the Universities of Bath, Bristol and Surrey. The project is funded by the Engineering and Physical Sciences Research Council (EPSRC) Grant EP/R013179/1.

\section{References}

[1] C. Rhodes, Briefing Paper Number 01942. Manufacturing: statistics and policy, The House of Commons Library research service, UK, 2020.

[2] UKRI. Manufacturing the future. 2021 [cited 202124 February]; Available from: https://epsrc.ukri.org/research/ourportfolio/themes/manufacturingthefuture/.

[3] The University of Bath. TRansdisciplinary Engineering Design (TREND). 2021 [cited 202124 February]; Available from: https:/www.bath.ac.uk/projects/transdisciplinary-engineering-design-trend/. 
[4] L. Newnes, et al., TRansdisciplinary ENgineering Design (TREND): Towards a Transdisciplinary Engineering Index. Advances in Transdisciplinary Engineering, 2020, Vol. 12, pp. 42-49.

[5] L. Apostel, Interdisciplinarity: Problems of teaching and research in Universities, OECD, 1972.

[6] S, Lattanzio, et al., Concepts of Transdisciplinary Engineering: A Transdisciplinary Landscape, The International Journal of Agile Systems and Management, Accepted 2021.

[7] C. Pohl, From Transdisciplinarity to Transdisciplinary Research. Transdisciplinary Journal of Engineering \& Science, 2010, Vol. 1, pp. 65-73.

[8] C. Pohl and G.H. Hadorn, Principles for Desigining Transdisciplinary Research, Swiss Academies of Arts and Sciences, Bern, 2007.

[9] B. Tress, G. Tress, and G. Fry, Clarifying integrative research concepts in landscape ecology, Landscape Ecology, 2004, pp. 479-493.

[10] F. Wickson, A.L. Carew, and A.W. Russell, Transdisciplinary research: characteristics, quandaries and quality, Futures, 2006, Vol. 38(9), pp. 1046-1059.

[11] T. Augsburg, Becoming Transdisciplinary: The Emergence of the Transdisciplinary Individual. World Futures, 2014, Vol. 70(3-4), pp. 233-247.

[12] J.H. Bernstein, Transdisciplinarity: A Review of Its Origins, Development, and Current Issues. Journal of Research Practice, 2015, Vol. 11, Article R1.

[13] S. Lattanzio, et al., Transdisciplinarity Within the Academic Engineering Literature, International Journal of Agile Systems and Management, 2020, Vol. 13(2), pp. 213-232.

[14] R.W. Scholz and G. Steiner, Transdisciplinarity at the crossroads. Sustainability Science, 2015, Vol. 10(4), pp. 521-526.

[15] E. Carey, et al., Foraging for Transdisciplinary Challenges: Emergent Industrial Themes, in Advances in Transdisciplainry Engineering, 2021, in press.

[16] R. Lawrence, Deciphering interdisciplinary and transdisciplinary contributions. Transdisciplinary Journal of Engineering and Science, 2010, Vol. 1(1), pp. 125-130.

[17] C, Pohl, What is progress in transdisciplinary research? Futures, 2011, Vol. 43(6), pp. 618-626.

[18] Swiss Academies of Arts and Sciences. td-net Network for Transdisciplinary Research. 2018 27th July 2020]; Available from: http://www.transdisciplinarity.ch/en/td-net/Transdisziplinarit$\mathrm{t} /$ Definitionen.html.

[19] T. Mettler, A design science research perspective on maturity models in information systems. Institute of Information Management, Universtiy of St. Gallen, 2009.

[20] A.M. Maier, J. Moultrie, and P.J. Clarkson, Assessing organizational capabilities: Reviewing and guiding the development of maturity grids. IEEE Transactions on Engineering Management, 2012, Vol. 59(1), pp. 138-159.

[21] P. Fraser J. Moultrie, and M. Gregory. The use of maturity models/grids as a tool in assessing product development capability. IEEE International Engineering Management Conference, 2002.

[22] J. Becker, R. Knackstedt, and J. Pöppelbuß, Developing maturity models for it management - A procedure model and its application. Business and Information Systems Engineering, 2009. Vol. 51(3), pp. 249-260.

[23] T. de Bruin, et al. Understanding the main phases of developing a maturity assessment model. ACIS 2005 Proceedings - 16th Australasian Conference on Information Systems. 2005.

[24] J.C.R. Hauck, et al., Proposing an ISO/IEC 15504-2 compliant method for process capability/maturity models customization, Lecture Notes in Computer Science (including subseries Lecture Notes in Artificial Intelligence and Lecture Notes in Bioinformatics), 2011, pp. 44-58.

[25] A. Maier, J. Moultrie, and J. Clarkson, Developing maturity grids for assessing organizational capabilities: practitioner guide, 4th international conference on management consulting, Academy of Management (MCD 2009), 2009, Vienna. pp. 1-29.

[26] C.F. Salviano, et al., A method framework for engineering process capability models, EuroSPI 2009. 2009, pp. 625-636.

[27] M. Van Steenbergen, et al. The design of focus area maturity models. In: R. Winter et al. (eds.) Global Perspectives on Design Science Research, 2010, pp. 317-332.

[28] C.G. Von Wangenheim, et al., Creating software process capability/maturity models. IEEE Software, 2010, Vol. 27(4), pp. 92-94.

[29] G.A García-Mireles, M.Á. Moraga, and F. García. Development of maturity models: A systematic literature review. 16th International Conference on Evaluation \& Assessment in Software Engineering (EASE 2012), 2012, 10.1049/ic.2012.0036.

[30] The Carbon Trust. Energy management self-assessment tool. 2021 [cited 202124 February ]; Available from: https://www.carbontrust.com/resources/energy-management-self-assessment-tool.

[31] R. Ørngreen and K. Levinsen, Workshops as a research methodology. Electronic Journal of e-Learning, 2017, Vol. 15(1), pp. 70-81.

[32] T. Mettler, Maturity Assessment Models: A Design Science Research Approach. International Journal of Society Systems Science, 2011, Vol. 3(1/2), pp. 81-98. 


\section{Appendix 1: Disciplinary Maturity Grid}

\begin{tabular}{|c|c|c|c|c|c|c|}
\hline 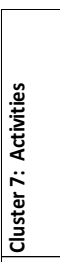 & 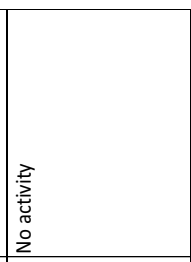 & 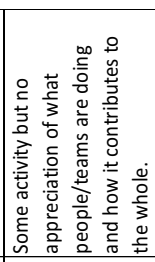 & 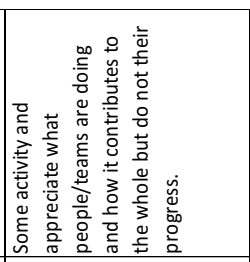 & 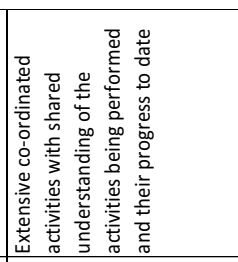 & 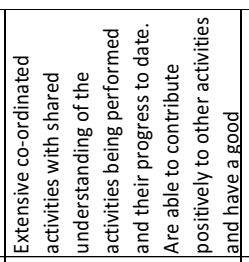 & \\
\hline 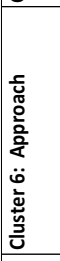 & 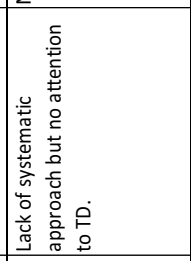 & 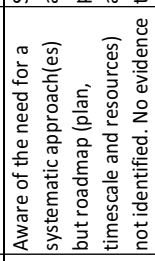 & 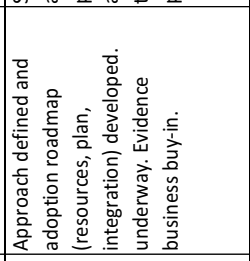 & 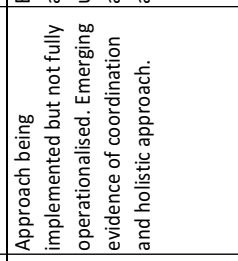 & 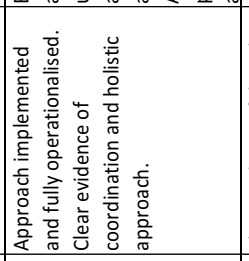 & 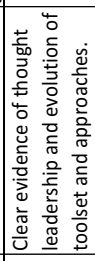 \\
\hline 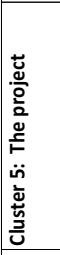 & 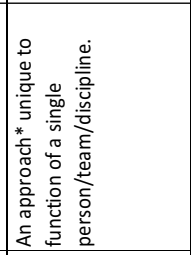 & 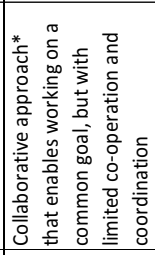 & 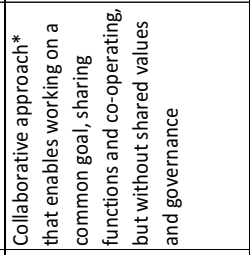 & 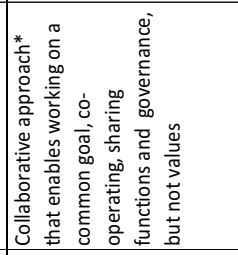 & 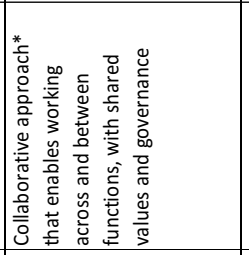 & \\
\hline 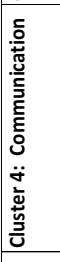 & 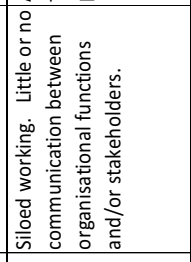 & 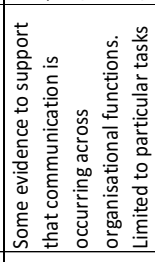 & 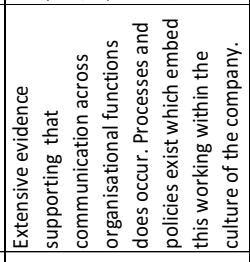 & 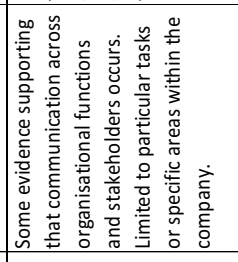 & 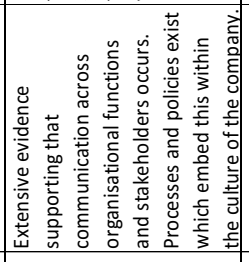 & \\
\hline 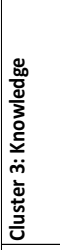 & 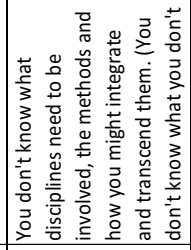 & 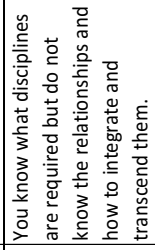 & 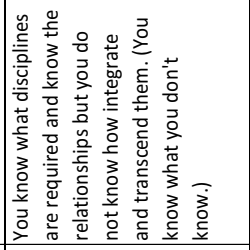 & 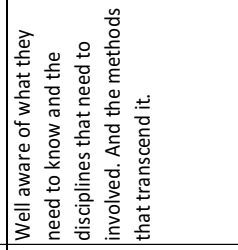 & 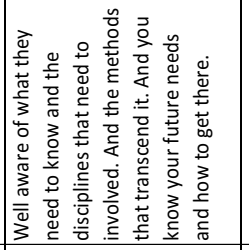 & \\
\hline 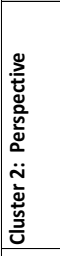 & 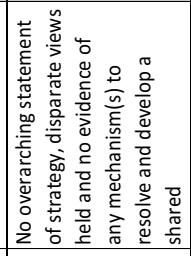 & 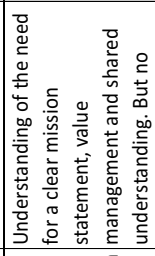 & 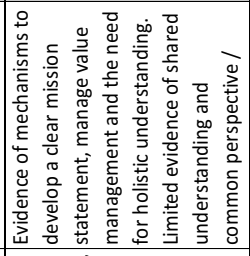 & 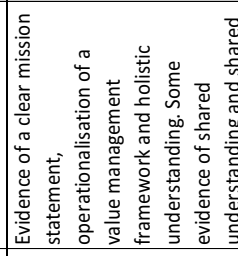 & 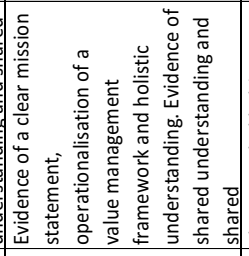 & 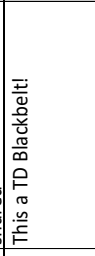 \\
\hline 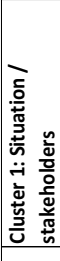 & 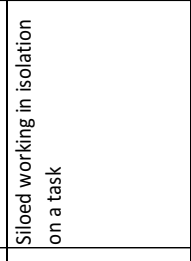 & 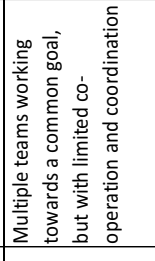 & 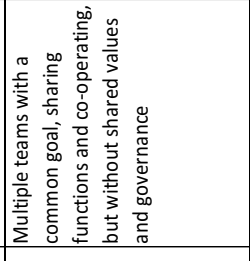 & 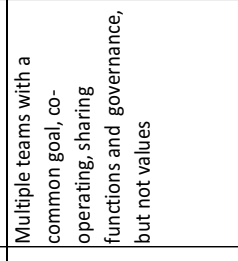 & 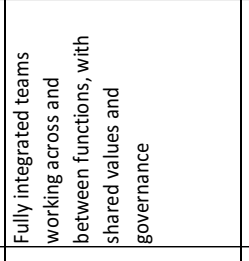 & \\
\hline & $\mid \overrightarrow{\bar{J}}$ & $\mid$ & $\frac{m}{\stackrel{m}{g}}$ & נָ & 迆 & 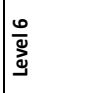 \\
\hline
\end{tabular}

